\title{
Obesogenic food consumption among young children: the role of maltreatment
}

\author{
Dylan B Jackson ${ }^{1, *}$ and Michael G Vaughn ${ }^{2,3}$ \\ 'Department of Criminal Justice, The University of Texas at San Antonio, 501 W. César E. Chàvez Blvd, San \\ Antonio, TX 78207, USA: ${ }^{2}$ College for Public Health \& Social Justice, Saint Louis University, St. Louis, MO, USA: \\ ${ }^{3}$ Yonsei University, Seoul, Republic of Korea
}

Submitted 6 February 2018: Final revision received 28 November 2018: Accepted 3 January 2019: First published online 15 February 2019

\begin{abstract}
Objective: To determine whether children exposed to a greater variety of acts of parent-to-child physical and psychological maltreatment will be at greater risk of consuming obesogenic foods at a higher frequency.

Design: Survey research using a longitudinal panel design.

Setting: In-home interviews with primary caregivers in twenty large US cities.

Participants: A national sample of at-risk children and their families who participated in the Fragile Families and Child Wellbeing Study (FFCWS).

Results: Child maltreatment emerged as a statistically significant $(P<0 \cdot 01)$ and robust predictor of obesogenic food consumption, in both cross-sectional and longitudinal analyses. Child maltreatment also consistently emerged as one of the strongest predictors of obesogenic food consumption in these models. Ancillary analyses indicated that physical maltreatment plays a particularly important role in these associations.

Conclusions: A major implication of the present study is that child maltreatment prevention efforts should be reflected in interventions that seek to diminish unhealthy eating practices among children. Multi-professional teams can work together on obesity prevention not only via education but also by considering the interconnectedness of obesogenic food consumption and experiences of maltreatment.
\end{abstract}

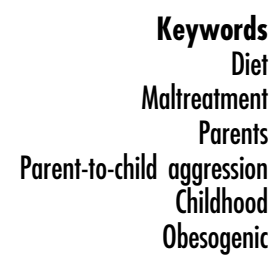

Scholars and practitioners the world over acknowledge the development of a global obesity pandemic during the past several decades ${ }^{(1-3)}$, driven in part by increases in obesogenic food consumption ${ }^{(4)}$. The youngest members of the population, moreover, have not been left unscathed by this pandemic, as children's body weights and consumption of sugary and processed foods have risen in tandem ${ }^{(2,5-9)}$. In addition to its clear association with $\mathrm{BMI}^{(10)}$ and waist circumference $^{(11)}$, greater intake of obesogenic foods among young children has also been linked to elevated blood pressure $^{(12)}$, reductions in intelligence quotient and cognitive skills ${ }^{(13)}$, diminished educational attainment ${ }^{(14)}$, poor mental health $^{(15)}$ and problem/violent behaviours ${ }^{(16,17)}$. In light of this growing body of research, it has become increasingly apparent that frequent consumption of obesogenic foods among children constitutes a critical threat to public health that requires continued empirical attention ${ }^{(18)}$.

Despite the large body of research examining risk factors for obesogenic diets among children, the possible connection between psychological and physical maltreatment and the consumption of obesogenic foods during childhood has generally been overlooked. Still, research on adverse childhood experiences, which typically include children's exposure to maltreatment and domestic violence, has suggested that child adversities are linked to various indicators of poor health ${ }^{(19)}$, including unhealthy dietary behaviours (e.g. disordered, compulsive or emotional eating) ${ }^{(20,21)}$, and the long-term risk of obesity ${ }^{(22,23)}$. The emerging connection between adverse childhood experiences (e.g. maltreatment), risky dietary behaviours and obesity has led some scholars to advocate for obesity prevention that is informed by the trauma incurred from childhood adversities ${ }^{(24)}$. These prevention efforts echo literature suggesting that the link between adverse childhood experiences, obesity and risk factors for obesity (e.g. low diet quality) may be partly explained by the destabilizing effects of adverse childhood experiences, namely 'mental and emotional perturbations' and 'maladaptive coping responses ${ }^{,(25)}$. Related empirical investigations, moreover, have linked childhood adversities to negative affect, emotional dysregulation and emotional eating ${ }^{(21)}$, which may emerge at fairly early life stages ${ }^{(26)}$, particularly in the context of lower executive function ${ }^{(27)}$.

In addition to the literature on adverse childhood experiences and health outcomes, a broader array of studies suggest a number of reasons to suspect an association 
between early maltreatment experiences and child dietary behaviours. First, the experience of psychological and/or physical maltreatment during the early years of life can involve incredibly stressful and even traumatizing experiences that can tax mental and physical wellbeing ${ }^{(28)}$. Early childhood adversities of this nature have been found to impact long-term health ${ }^{(29,30)}$ and health behaviours ${ }^{(31)}$, and therefore may also be associated with more proximate obesogenic dietary practices by heightening stress and associated emotional eating behaviours during childhood ${ }^{(21,32)}$. Second, exposure to chronic interpersonal trauma during childhood, such as physical and psychological maltreatment, can alter the neural circuitry that underpins both cognitive control and the emotional processing linked to the assessment of threat and reward ${ }^{(33)}$. Such alterations can lead to higher incidences of dysregulated affect, deficits in memory and attention, and diminished impulse control ${ }^{(34,35)}$. Importantly, children who exhibit these traits early in the life course are also at risk of engaging in dietary behaviours that are obesogenic ${ }^{(27,36)}$. Finally, prior research has indicated that, on average, children of parents who are more authoritarian in their parenting styles are at higher risk of obesogenic dietary practices ${ }^{(37,38)}$. Since authoritarian parenting is often typified by high demands, low nurturance and low tolerance for mistakes, psychological and physical maltreatment may simply constitute manifestations of an extreme form of this maladaptive parenting style ${ }^{(37,38)}$.

Little empirical scrutiny of the nexus between child maltreatment and obesogenic food consumption during early childhood has been undertaken. Despite the relative dearth of literature on this topic, some studies have revealed an association between maltreatment and child micronutrient status. For instance, in the USA, maltreated children have been found to exhibit significantly lower dietary micronutrient intake (e.g. vitamin $\mathrm{D}$, zinc) ${ }^{(39)}$, and in a Chinese sample, higher rates of non-anaemic iron deficiency ${ }^{(40)}$. These findings may partly reflect an inadequate intake of foods that may otherwise enhance micronutrient status or bioavailability in children ${ }^{(41,42)}$. Even so, more research on the link between maltreatment and child dietary behaviours is certainly warranted. In the present study, we assess the association between multiple forms of child maltreatment and obesogenic food consumption using a longitudinal study of at-risk children and families in the USA.

\section{Materials and methods}

\section{Participants}

Data for the present study come from the Fragile Families and Child Wellbeing Study (FFCWS). The FFCWS is a national, longitudinal study of approximately 4800 children who were born between the years of 1998 and 2000, and includes six waves of data collection to date. The FFCWS data were obtained through a multi-staged, clustered sampling procedure. To be precise, the sampling strategy was designed to oversample unmarried, low-income couples with one or more children. Ultimately, a stratified random sample of twenty US cities was selected from the population of cities with 200000 or more residents. The next sampling stage involved the selection of seventy-five hospitals within these twenty cities, which was followed by a random sample of couples (mostly unmarried) who had just given birth to a child and who consented to participate in the study. The sampling strategy resulted in the oversampling of low-income couples as well as unmarried couples, with $75 \%$ of couples being unmarried and $36 \%$ of couples falling below the poverty line at wave 1 . Consequently, the FFCWS sample is at relatively high risk of various adverse health and developmental outcomes, and is therefore well suited to the study of different forms of child maltreatment and their associations with the consumption of obesogenic foods.

\section{Measures}

\section{Obesogenic food consumption index}

As a means of assessing overall patterns of obesogenic food consumption, we constructed a standardized index in which participants' scores on each of four obesogenic food items - salty snacks, sweets, soda and fast food were standardized and then averaged together to create the obesogenic food consumption index $(\alpha=0 \cdot 70)$.

\section{Salty snacks, sweets, soda and fast food}

At the fourth wave of data collection, when focal children were approximately 5 years old, primary caregivers (typically the mother) were asked during the in-home interview about their child's eating habits. Specifically, primary caregivers were asked, 'On a typical day, about how many servings of the following foods does (CHILD) eat?' Items included chips and other snack foods high in salt/sodium (e.g. pretzels); candy and other foods that were high in sugar (e.g. cookies, cakes, etc.); and soda (e.g. Coke, Pepsi). Response options to this item included 'none' $(=0)$, one serving $(=1)$, '2 servings' $(=2)$, '3 servings' (=3), '4 servings' $(=4)$ and ' 5 or more servings' $(=5)$. Thus, higher scores on these items reflect more frequent daily consumption of these foods. At this same wave, primary caregivers were also asked, 'About how many times a week does (CHILD) eat a meal from a "fast food” restaurant (e.g. McDonald's, KFC, etc.)?' Response options to this item included 'none or hardly ever' $(=0)$, 'one time' $(=1)$, 'two times' $(=2)$, 'three times' $(=3)$, 'four times' $(=4)$ and 'five or more times' $(=5)$. Thus, higher scores on this item reflect more frequent weekly consumption of fast food. 


\section{Psychological maltreatment}

Measures of child maltreatment were assessed at the third and fourth waves of data collection, when children were approximately 3 and 5 years old. In line with prior research $^{(43)}$, we employed five items from the ParentChild Conflict Tactics Scale (CTS-PC) to determine the extent of psychological maltreatment of children in the home at wave 3 and wave 4 of data collection ${ }^{(44)}$. The items were asked of a sub-sample of households who participated in the in-home surveys at waves 3 and 4 . These items include the following: shouted, yelled or screamed at the child; swore or cursed at the child; told the child you would send them away or kick them out of the house; threatened to spank or hit the child without actually doing it; and calling the child dumb, lazy or something similar. For each of these acts of psychological maltreatment, households in which primary caregivers (usually the mother) reported that they and/or a secondary caregiver (usually the father) engaged in these behaviours one or more times during the year prior to the interview were assigned a value of 1 . All other households with valid data were assigned a value of 0 on each of the psychologically abusive items ${ }^{(45)}$. Scores on each of the five items were summed to create a composite variety score in which higher scores reflect greater participation of caregivers in a variety of psychologically aggressive behaviours towards their children.

\section{Physical maltreatment}

As was the case with psychological maltreatment, we followed prior research ${ }^{(43)}$ and employed five items from the CTS-PC that were available in the FFCWS at the third and fourth waves of data collection in order to assess physical maltreatment (i.e. acts of physical aggression by caregivers towards their child). These items include the following: shook the child; hit the child with a hard object (e.g. belt); spanked the child; slapped the child; and pinched the child. For each of these acts of physical mistreatment, households in which primary caregivers (usually the mother) reported that they and/or a secondary caregiver (usually the father) engaged in these behaviours one or more times during the year prior to the interview were assigned a value of 1 . All other households with valid data were assigned a value of 0 on each of the physically abusive items. Scores on each of the five items were summed to create a composite variety score in which higher scores reflect greater participation of caregivers in a variety of physically aggressive behaviours towards their children.

\section{Total maltreatment}

Using data from wave 3 and wave 4 of data collection, we also created a variety measure based on both the binary psychological maltreatment items and the binary physical maltreatment items. At each of the examined waves (i.e. 3 and 4), these ten items were summed to create a composite variety score at waves 3 and 4 (i.e. total maltreatment W3, total maltreatment W4) in which higher scores reflect greater participation of caregivers in a variety of both psychologically and physically aggressive behaviours towards their children. Finally, we created a composite measure of total maltreatment in which participants' scores on the wave 3 and wave 4 total maltreatment measures were averaged.

\section{Covariates}

Several covariates were employed in statistical analyses to account for potential confounding, including maternal age, race, education, smoking, drinking and BMI. We also included measures of maternal depression and impulsivity, levels of parenting stress, whether or not a parent in the household was incarcerated, and household poverty.

\section{Analytic plan}

First, descriptive statistics pertaining to the key variables of interest were calculated and presented. Next, bivariate relationships between child maltreatment and obesogenic food consumption were examined by calculating children's percentile scores on maltreatment by their degree of exposure to various types of maltreatment. Finally, multivariate regression techniques were employed to examine the relationship between the indicators of obesogenic food consumption and the various maltreatment measures, with additional multivariate models examining the possible connection between maltreatment and specific subdimensions of obesogenic food consumption.

\section{Results}

First, univariate statistics for all the variables pertaining to the subsequent analyses are presented. Second, the zeroorder relationship between child maltreatment and obesogenic food consumption is explored by plotting percentile scores on the obesogenic food consumption index by the degree of psychological, physical and total child maltreatment. Finally, multivariate regression models are employed to investigate whether any previously detected bivariate associations between child maltreatment during late infancy and early childhood and obesogenic eating patterns among children are robust to the inclusion of the eleven covariates included in the present study. Ancillary analyses are also conducted to examine any variation in the results by each of the different dimensions of obesogenic foods (i.e. salty snacks, sweets, soda and fast food).

As shown in Table 1, the obesogenic food items ranged from 0 to 5, with the consumption of fast food occurring just over twice per week, on average. Additionally, children consumed, on average, less than one soda per day (0.756) and between 1 and 2 servings of sweets and salty snacks per day (on average). Moreover, the results suggest that 
Table 1 Descriptive statistics of the study participants, a national sample of at-risk children and their families from twenty large US cities who participated in the Fragile Families and Child Wellbeing Study (FFCWS)

\begin{tabular}{|c|c|c|c|c|}
\hline & Mean & $\%$ & SD & Range \\
\hline \multicolumn{5}{|l|}{ Outcome measures } \\
\hline Obesogenic food consumption index & 0.000 & - & 0.713 & $-1 \cdot 181-3.341$ \\
\hline Salty snacks (servings/d)* & 1.653 & _ & 1.144 & $0-5$ \\
\hline Sweets (servings/d)* & 1.328 & - & 1.189 & $0-5$ \\
\hline Soda (servings/d)* & 0.756 & - & 1.135 & $0-5$ \\
\hline Fast food (servings/d)* & $2 \cdot 233$ & - & 1.044 & $0-5$ \\
\hline \multicolumn{5}{|l|}{ Child maltreatment measures $\dagger$} \\
\hline Psychological maltreatment (W3) & 1.937 & - & 0.953 & $0-5$ \\
\hline Psychological maltreatment (W4) & $2 \cdot 137$ & - & 1.026 & $0-5$ \\
\hline Composite psychological maltreatment & 2.066 & - & 0.837 & $0-5$ \\
\hline Physical maltreatment (W3) & 1.759 & - & 1.147 & $0-5$ \\
\hline Physical maltreatment (W4) & 1.749 & - & 1.227 & $0-5$ \\
\hline Composite physical maltreatment & 1.784 & - & 1.012 & $0-5$ \\
\hline Total maltreatment (W3) & 3.695 & - & 1.851 & $0-10$ \\
\hline Total maltreatment (W4) & 3.887 & - & 1.966 & $0-10$ \\
\hline Composite total maltreatment & 3.851 & - & 1.657 & $0-10$ \\
\hline \multicolumn{5}{|l|}{ Covariates } \\
\hline Maternal age (years) & $25 \cdot 276$ & - & 6.037 & $15-43$ \\
\hline Maternal race $($ non-White $=1)$ & - & $69 \cdot 2$ & - & $0-1$ \\
\hline Maternal education $\ddagger$ & 4.629 & - & 1.822 & $1-9$ \\
\hline Below poverty line & - & $40 \cdot 8$ & - & $0-1$ \\
\hline Maternal smoking & - & $30 \cdot 4$ & - & $0-1$ \\
\hline Maternal drinking & - & 65.9 & - & $0-1$ \\
\hline Maternal BMI§ & 0.000 & & 1.000 & $-2.090-5.627$ \\
\hline Maternal impulsivity & 2.032 & & 0.618 & $1-4$ \\
\hline Maternal depression & - & $17 \cdot 0$ & - & $0-1$ \\
\hline Parenting stress & $2 \cdot 111$ & & 0.763 & $1-5$ \\
\hline Parental incarceration & 0.535 & & 0.600 & $0-2$ \\
\hline
\end{tabular}

W3, wave 3; W4, wave 4

Child participants were born between 1998 and 2000; dietary measures were collected between 2003 and 2006, when children were approximately 5 years old; child maltreatment measures were collected at the 3-year follow-up (W3, 2001-2003, when children were approximately 3 years old) and the 5-year follow-up (W4, 2003-2006, when children were approximately 5 years old). Data were analysed for the current project in the summer and autumn of 2017.

${ }^{*} \mathrm{~A}$ score of 5 indicates 5 or more servings.

tMean scores indicate the average number of distinct forms of maltreatment within a particular dimension experienced by child participants.

$\ddagger$ Maternal education ranges from 'no formal schooling' $(=1)$ to 'graduate/professional school' $(=9)$. A mean score of 4.6 approximates the receipt of a high school diploma.

§The BMI item is standardized, with a mean of 0 and a SD of 1 .

|l Scores range from 'strongly disagree' $(=1)$ to 'strongly agree' $(=4)$, with maternal participants responding to statements concerning their own impulsivity. The average score on the items indicates that mothers tend to disagree that they behave impulsively.

ףHigher scores reflect greater agreement with statements indicative of parenting-related stress (e.g. 'trapped in my role as parent'), ranging from 'strongly disagree' $(=1)$ to 'strongly agree' $(=5)$. The mean score indicates that, on average, parents tend to disagree with statements concerning parent-related stress.

parents engaged in a slightly greater variety of psychologically abusive behaviours relative to physically abusive behaviours. In terms of covariates, mothers were 25 years old, on average, and $69 \%$ were non-White. Mothers' average education approximated a high school diploma, and more than $40 \%$ of households fell below the poverty line at wave 4 . Roughly $30 \%$ of mothers smoked, and just under $66 \%$ drank alcohol. Although standardized in the analyses, the average BMI in the final analytical sample approximated $29 \mathrm{~kg} / \mathrm{m}^{2}$, which falls within the overweight category. Finally, $17 \%$ of mothers met the clinical criteria for depression at wave 3 , and the prevalence of parental incarceration was fairly common, with more than half of children experiencing the incarceration of one or both of their parents.

Next, we examined bivariate associations between the psychological, physical and total maltreatment measures and obesogenic food consumption during childhood. These results are displayed in Fig. 1. Overall, these bivariate results show a consistent link between the number of acts of parent-to-child aggression, whether psychological or physical, and children's percentile score on the obesogenic food consumption index, namely salty snacks, sweets, soda and fast food. For instance, children exposed to a high number of psychologically abusive behaviours (i.e. at or above $1 \mathrm{sD}$ above the mean) had, on average, thirty-eight percentile points higher score on obesogenic food consumption than children who were infrequently (i.e. at or below $1 \mathrm{sD}$ below the mean) exposed to such abusive behaviours (i.e. 75th percentile $v$. 37 th percentile). The associations are similar, although slightly attenuated, in the case of physical maltreatment (76th percentile $v$. 44th percentile).

We examined the robustness of these bivariate associations by employing multivariate regression models that accounted for the previously described covariates that might explain the associations illustrated in Fig. 1 and potentially render them spurious. Overall, the results in Table 2 indicate that, regardless of the specific form of maltreatment, or the wave at which it is examined, child maltreatment is a statistically significant $(P<0.01)$ and robust predictor of obesogenic food consumption, in both cross-sectional and longitudinal analyses (psychological 


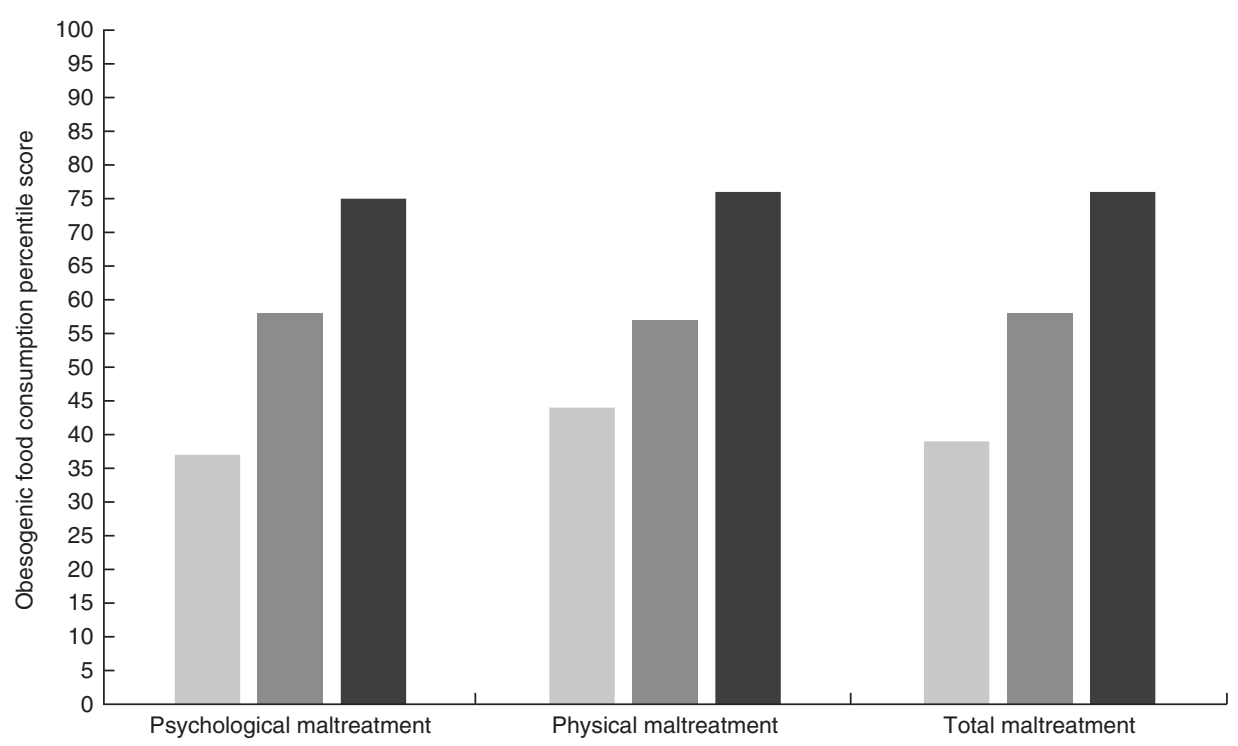

Fig. 1 Percentile score on obesogenic food consumption by type and degree ( $\square$, low; $\square$, average; $\square$, high) of child maltreatment in a national sample of at-risk children and their families from twenty large US cities who participated in the Fragile Families and Child Wellbeing Study (FFCWS). Child participants were born between 1998 and 2000; dietary measures were collected between 2003 and 2006, when children were approximately 5 years old; child maltreatment measures were collected at the 3-year follow-up (W3, 2001-2003, when children were approximately 3 years old) and the 5-year follow-up (W4, 2003-2006, when children were approximately 5 years old). Data were analysed for the current project in the summer and autumn of 2017.

maltreatment W3: $B=0 \cdot 086, \quad \mathrm{sE}=0 \cdot 020 ;$ psychological maltreatment W4: $B=0 \cdot 102, \quad \mathrm{SE}=0 \cdot 018 ; \quad$ composite: $B=0 \cdot 130, \mathrm{sE}=0 \cdot 024 ;$ physical maltreatment W3: $B=0 \cdot 093$, $\mathrm{SE}=0 \cdot 017$; physical maltreatment W4: $B=0 \cdot 111, \mathrm{SE}=0 \cdot 015$; composite: $B=0 \cdot 153, \mathrm{sE}=0 \cdot 019$; total maltreatment W3: $B=0.060, \mathrm{SE}=0.011$; total maltreatment W4: $B=0.074$, $\mathrm{SE}=0 \cdot 010$; composite: $B=0 \cdot 093, \mathrm{sE}=0 \cdot 012$ ).

Importantly, the various coefficients pertaining to child maltreatment maintain statistical significance independent of multiple household and parental risk factors (e.g. poverty, maternal education, parental incarceration, parenting stress, maternal depression, maternal impulsivity, etc.). Standardized coefficients for total maltreatment in models 7-9, moreover, are uniformly larger than the standardized coefficients for all other variables in the model, suggesting that total child maltreatment is consistently the best predictor of obesogenic food consumption in these models. This is also true of models 2-6. In model 1, the standardized coefficient pertaining to psychological maltreatment W3 is only surpassed by the standardized coefficient pertaining to maternal education. The standardized coefficient (i.e. $\beta$ ) representing the effect of the composite total maltreatment measure on obesogenic food consumption in model 9 is $0 \cdot 184$. In this model, the standardized coefficient for composite total maltreatment is nearly 3.5 times as large as the standardized coefficient for poverty $(\beta=0.053)$, more than 2.5 times as large as the standardized coefficient for parental incarceration $(\beta=0.073)$ and nearly twice as large as the standardized coefficient for maternal impulsivity $(\beta=0 \cdot 099)$.

Ancillary analyses that further explore the robustness of the findings in Table 2 are displayed in Table 3. Each of the obesogenic food dimensions - salty snacks, sweets, soda and fast food - is examined, as well as the obesogenic food consumption index. Specifically, Table 3 examines the competing effects of the composite measures of psychological and physical maltreatment on the four obesogenic food dimensions and obesogenic food consumption. Although it is useful to look at these maltreatment dimensions separately (as was the case in Table 2), it is also of value to explore the relative influence of each maltreatment dimension while accounting for the other, and the implications of the statistical overlap between them for the consumption of foods from the various obesogenic food dimensions. Although the correlation between the composite measures of physical and psychological maltreatment was 0.60 , tests of multicollinearity did not detect a problematic degree of multicollinearity in the multivariate models (psychological maltreatment: variance inflation factor $\leq 1.63$ in each of the models in Table 3; physical maltreatment: variance inflation factor $\leq 1.62$ in each of the models in Table 3 ). Ultimately, ancillary results indicate that the associations between physical maltreatment and the consumption of various obesogenic foods are consistently robust to the influence of psychological maltreatment on obesogenic food consumption. Associations between psychological maltreatment and consumption of various obesogenic foods, however, are attenuated to statistical nonsignificance once physical maltreatment is taken into account, with the sole exception of models examining soda consumption. Thus, it appears that, in most cases, previously detected associations between psychological maltreatment and the consumption of obesogenic foods 
Table 2 The link between psychological, physical and total maltreatment of children and obesogenic food consumption in a national sample of at-risk children and their families from twenty large US cities who participated in the Fragile Families and Child Wellbeing Study (FFCWS)

\begin{tabular}{|c|c|c|c|c|c|c|c|c|c|c|c|c|c|c|c|c|c|c|c|c|}
\hline \multirow[b]{3}{*}{ Variable } & \multicolumn{20}{|c|}{ Obesogenic food consumption index (W4) } \\
\hline & \multicolumn{2}{|c|}{ Model 1} & \multicolumn{2}{|c|}{ Model 2} & \multicolumn{2}{|c|}{ Model 3} & \multirow[b]{2}{*}{ Variable } & \multicolumn{2}{|c|}{ Model 4} & \multicolumn{2}{|c|}{ Model 5} & \multicolumn{2}{|c|}{ Model 6} & \multirow[b]{2}{*}{ Variable } & \multicolumn{2}{|c|}{ Model 7} & \multicolumn{2}{|c|}{ Model 8} & \multicolumn{2}{|c|}{ Model 9} \\
\hline & $B, \beta$ & SE & $B, \beta$ & SE & $B, \beta$ & SE & & $B, \beta$ & SE & $B, \beta$ & SE & $B, \beta$ & $\mathrm{SE}$ & & $B, \beta$ & $\mathrm{SE}$ & $B, \beta$ & $\mathrm{SE}$ & $B, \beta$ & $\mathrm{SE}$ \\
\hline $\begin{array}{l}\text { Psychological } \\
\text { maltreatment (W3) }\end{array}$ & $\begin{array}{l}0.086^{*} \\
0.098\end{array}$ & 0.020 & - & & - & & $\begin{array}{l}\text { Physical } \\
\text { maltreatment } \\
\text { (W3) }\end{array}$ & $\begin{array}{l}0.093^{\star} \\
0.128\end{array}$ & 0.017 & - & & - & & $\begin{array}{l}\text { Total } \\
\text { maltreatment } \\
\text { (W3) }\end{array}$ & $\begin{array}{l}0.060^{*} \\
0.133\end{array}$ & 0.011 & - & & - & \\
\hline $\begin{array}{l}\text { Psychological } \\
\text { maltreatment (W4) }\end{array}$ & - & & $\begin{array}{l}0.102^{*} \\
0.124\end{array}$ & 0.018 & - & & $\begin{array}{l}\text { Physical } \\
\text { maltreatment } \\
\text { (W4) }\end{array}$ & - & & $\begin{array}{l}0.111^{*} \\
0.163\end{array}$ & 0.015 & - & & $\begin{array}{l}\text { Total } \\
\text { maltreatment } \\
\text { (W4) }\end{array}$ & - & & $\begin{array}{l}0.074^{\star} \\
0.171\end{array}$ & 0.010 & - & \\
\hline $\begin{array}{l}\text { Composite } \\
\text { psychological } \\
\text { maltreatment }\end{array}$ & - & & - & & $\begin{array}{l}0.130^{*} \\
0.131\end{array}$ & 0.024 & $\begin{array}{l}\text { Composite } \\
\text { physical } \\
\text { maltreatment }\end{array}$ & - & & - & & $\begin{array}{l}0.153^{\star} \\
0.186\end{array}$ & 0.019 & $\begin{array}{l}\text { Composite } \\
\text { total } \\
\text { maltreatment }\end{array}$ & - & & - & & $\begin{array}{l}0.093^{\star} \\
0.184\end{array}$ & 0.012 \\
\hline Maternal age & $\begin{array}{l}0.002 \\
0.015\end{array}$ & 0.004 & $\begin{array}{l}0.003 \\
0.012\end{array}$ & 0.003 & $\begin{array}{l}0.003 \\
0.020\end{array}$ & 0.004 & Maternal age & $\begin{array}{l}0.003 \\
0.022\end{array}$ & 0.004 & $\begin{array}{l}0.002 \\
0.015\end{array}$ & 0.003 & $\begin{array}{l}0.003 \\
0.022\end{array}$ & 0.003 & Maternal age & $\begin{array}{l}0.003 \\
0.023\end{array}$ & 0.004 & $\begin{array}{l}0.003 \\
0.021\end{array}$ & 0.003 & $\begin{array}{l}0.004 \\
0.027\end{array}$ & 0.003 \\
\hline Maternal race & $\begin{array}{l}0.143^{*} \\
0.078\end{array}$ & 0.043 & $\begin{array}{l}0.127^{*} \\
0.069\end{array}$ & 0.041 & $\begin{array}{l}0.141^{\star}, \\
0.077\end{array}$ & 0.043 & Maternal race & $\begin{array}{l}0.114^{\star} \\
0.063\end{array}$ & 0.044 & $\begin{array}{l}0.090^{*} \\
0.049\end{array}$ & 0.041 & $\begin{array}{l}0.090^{\star} \\
0.049\end{array}$ & 0.043 & Maternal race & $\begin{array}{l}0.122^{*} \\
0.067\end{array}$ & 0.043 & $\begin{array}{l}0.010^{*} \\
0.054\end{array}$ & 0.041 & $\begin{array}{l}0.106^{*} \\
0.058\end{array}$ & 0.043 \\
\hline Maternal education & $\begin{array}{l}-0.051^{*} \\
-0.109\end{array}$ & 0.013 & $\begin{array}{l}-0.053^{*} \\
-0.111\end{array}$ & 0.012 & $\begin{array}{l}-0.052^{*} \\
-0.110\end{array}$ & 0.013 & $\begin{array}{l}\text { Maternal } \\
\text { education }\end{array}$ & $\begin{array}{l}-0.053^{*} \\
-0.112\end{array}$ & 0.013 & $\begin{array}{l}-0.053^{\star} \\
-0.112\end{array}$ & 0.012 & $\begin{array}{l}-0.053^{*} \\
-0.113\end{array}$ & 0.013 & $\begin{array}{l}\text { Maternal } \\
\text { education }\end{array}$ & $\begin{array}{l}-0.053^{\star} \\
-0.113\end{array}$ & 0.013 & $\begin{array}{l}-0.053^{*} \\
-0.111\end{array}$ & 0.012 & $\begin{array}{l}-0.053^{*} \\
-0.114\end{array}$ & 0.013 \\
\hline Below poverty line & $\begin{array}{l}0.084 \\
0.050\end{array}$ & 0.043 & $\begin{array}{l}0.096^{*} \\
0.057\end{array}$ & 0.041 & $\begin{array}{l}0.087^{*} \\
0.052\end{array}$ & 0.043 & $\begin{array}{l}\text { Below poverty } \\
\text { line }\end{array}$ & $\begin{array}{l}0.088^{\star} \\
0.053\end{array}$ & 0.043 & $\begin{array}{l}0.091^{\star} \\
0.054\end{array}$ & 0.041 & $\begin{array}{l}0.088^{\star} \\
0.053\end{array}$ & 0.043 & $\begin{array}{l}\text { Below } \\
\text { poverty } \\
\text { line }\end{array}$ & $\begin{array}{l}0.085^{\star} \\
0.051\end{array}$ & 0.043 & $\begin{array}{l}0.094^{*} \\
0.056\end{array}$ & 0.041 & $\begin{array}{l}0.088^{*} \\
0.053\end{array}$ & 0.043 \\
\hline Maternal smoking & $\begin{array}{l}0.075 \\
0.042\end{array}$ & 0.043 & $\begin{array}{l}0.068 \\
0.038\end{array}$ & 0.041 & $\begin{array}{l}0.070 \\
0.039\end{array}$ & 0.043 & $\begin{array}{l}\text { Maternal } \\
\text { smoking }\end{array}$ & $\begin{array}{l}0.068 \\
0.038\end{array}$ & 0.043 & $\begin{array}{l}0.087^{\star} \\
0.049\end{array}$ & 0.040 & $\begin{array}{l}0.074 \\
0.041\end{array}$ & 0.042 & $\begin{array}{l}\text { Maternal } \\
\text { smoking }\end{array}$ & $\begin{array}{l}0.069 \\
0.039\end{array}$ & 0.043 & $\begin{array}{l}0.076^{\star} \\
0.042\end{array}$ & 0.040 & $\begin{array}{l}0.069 \\
0.039\end{array}$ & 0.042 \\
\hline Maternal drinking & $\begin{array}{l}0.027 \\
0.016\end{array}$ & 0.039 & $\begin{array}{l}0.040 \\
0.024\end{array}$ & 0.037 & $\begin{array}{l}0.018 \\
0.011\end{array}$ & 0.039 & $\begin{array}{l}\text { Maternal } \\
\text { drinking }\end{array}$ & $\begin{array}{l}0.017 \\
0.010\end{array}$ & 0.039 & $\begin{array}{l}0.030 \\
0.018\end{array}$ & 0.037 & $\begin{array}{l}-0.001 \\
-0.001\end{array}$ & 0.039 & $\begin{array}{l}\text { Maternal } \\
\text { drinking }\end{array}$ & $\begin{array}{l}0.011 \\
0.007\end{array}$ & 0.039 & $\begin{array}{l}0.025 \\
0.015\end{array}$ & 0.037 & $\begin{array}{l}-0.005 \\
-0.003\end{array}$ & 0.039 \\
\hline Maternal BMI & $\begin{array}{l}-0.001 \\
-0.009\end{array}$ & 0.002 & $\begin{array}{l}-0.001 \\
-0.009\end{array}$ & 0.002 & $\begin{array}{l}-0.001 \\
-0.009\end{array}$ & 0.002 & Maternal BMI & $\begin{array}{l}-0.001 \\
-0.008\end{array}$ & 0.002 & $\begin{array}{l}-0.002 \\
-0.015\end{array}$ & 0.002 & $\begin{array}{l}-0.002 \\
-0.015\end{array}$ & 0.002 & Maternal BMI & $\begin{array}{l}-0.001 \\
-0.009\end{array}$ & 0.002 & $\begin{array}{l}-0.002 \\
-0.014\end{array}$ & 0.002 & $\begin{array}{l}-0.001 \\
-0.014\end{array}$ & 0.002 \\
\hline Maternal impulsivity & $\begin{array}{l}0.141^{*} \\
0.103\end{array}$ & 0.033 & $\begin{array}{l}0.133^{*} \\
0.095\end{array}$ & 0.031 & $\begin{array}{l}0.137^{\star} \\
0.010\end{array}$ & 0.033 & $\begin{array}{l}\text { Maternal } \\
\text { impulsivity }\end{array}$ & $\begin{array}{l}0.147^{\star} \\
0.107\end{array}$ & 0.033 & $\begin{array}{l}0.132^{*} \\
0.095\end{array}$ & 0.031 & $\begin{array}{l}0.140^{*} \\
0.102\end{array}$ & 0.032 & $\begin{array}{l}\text { Maternal } \\
\text { impulsivity }\end{array}$ & $\begin{array}{l}0.142^{\star} \\
0.104\end{array}$ & 0.033 & $\begin{array}{l}0.129^{*} \\
0.092\end{array}$ & 0.031 & $\begin{array}{l}0.135^{*} \text {, } \\
0.099\end{array}$ & 0.032 \\
\hline Maternal depression & $\begin{array}{l}-0.039 \\
-0.018\end{array}$ & 0.051 & $\begin{array}{l}-0.044 \\
-0.020\end{array}$ & 0.049 & $\begin{array}{l}-0.051 \\
-0.023\end{array}$ & 0.026 & $\begin{array}{l}\text { Maternal } \\
\text { depression }\end{array}$ & $\begin{array}{l}-0.026 \\
-0.012\end{array}$ & 0.051 & $\begin{array}{l}-0.036 \\
-0.016\end{array}$ & 0.048 & $\begin{array}{l}-0.036 \\
-0.017\end{array}$ & 0.050 & $\begin{array}{l}\text { Maternal } \\
\text { depression }\end{array}$ & $\begin{array}{l}-0.033 \\
-0.015\end{array}$ & 0.051 & $\begin{array}{l}-0.048 \\
-0.021\end{array}$ & 0.048 & $\begin{array}{l}-0.048 \\
-0.022\end{array}$ & 0.051 \\
\hline Parenting stress & $\begin{array}{l}0.039 \\
0.036\end{array}$ & 0.026 & $\begin{array}{l}0.014 \\
0.013\end{array}$ & 0.025 & $\begin{array}{l}0.026 \\
0.024\end{array}$ & 0.026 & $\begin{array}{l}\text { Parenting } \\
\text { stress }\end{array}$ & $\begin{array}{l}0.036 \\
0.033\end{array}$ & 0.026 & $\begin{array}{l}0.012 \\
0.011\end{array}$ & 0.024 & $\begin{array}{l}0.021 \\
0.019\end{array}$ & 0.026 & $\begin{array}{l}\text { Parenting } \\
\text { stress }\end{array}$ & $\begin{array}{l}0.033 \\
0.031\end{array}$ & 0.026 & $\begin{array}{l}0.004 \\
0.004\end{array}$ & 0.025 & $\begin{array}{l}0.015 \\
0.014\end{array}$ & 0.026 \\
\hline Parental incarceration & $\begin{array}{l}0.112^{*} \\
0.080\end{array}$ & 0.034 & $\begin{array}{l}0.126^{\star} \\
0.089\end{array}$ & 0.033 & $\begin{array}{l}0.109^{*}, \\
0.077\end{array}$ & 0.034 & $\begin{array}{l}\text { Parental } \\
\text { incarceration }\end{array}$ & $\begin{array}{l}0.115^{\star} \\
0.082\end{array}$ & 0.034 & $\begin{array}{l}0.117^{\star} \\
0.083\end{array}$ & 0.033 & $\begin{array}{l}0.105^{*} \\
0.076\end{array}$ & 0.034 & $\begin{array}{l}\text { Parental } \\
\text { incarceration }\end{array}$ & $\begin{array}{l}0.110^{*} \\
0.079\end{array}$ & 0.034 & $\begin{array}{l}0.116^{\star} \\
0.083\end{array}$ & 0.033 & $\begin{array}{l}0.101^{*} \\
0.073\end{array}$ & 0.034 \\
\hline$n$ & 180 & & 200 & & 180 & & $n$ & 178 & & 200 & & 178 & & $n$ & 178 & & 200 & & 178 & \\
\hline
\end{tabular}

W4, wave 4; $B$, unstandardized coefficient; $\beta$, standardized coefficient; $W 3$, wave 3.

Child participants were born between 1998 and 2000; dietary measures were collected between 2003 and 2006, when children were approximately 5 years old; child maltreatment measures were collected at the 3-year follow-up (W3, 2001-2003, when children were approximately 3 years old) and the 5-year follow-up (W4, 2003-2006, when children were approximately 5 years old). Data were analysed for the current project in the summer and autumn of 2017 .

${ }^{\star} P<0.05$. 
Table 3 Child maltreatment and obesogenic food dimensions: psychological, physical, or both? Associations in a national sample of at-risk children and their families from twenty large US cities who participated in the Fragile Families and Child Wellbeing Study (FFCWS)

\begin{tabular}{|c|c|c|c|c|c|c|c|c|c|c|}
\hline \multirow[b]{4}{*}{ Variable } & \multicolumn{10}{|c|}{ Obesogenic food consumption (W4) } \\
\hline & \multicolumn{2}{|c|}{ Salty snacks } & \multicolumn{2}{|l|}{ Sweets } & \multicolumn{2}{|l|}{ Soda } & \multicolumn{2}{|l|}{ Fast food } & \multicolumn{2}{|l|}{ Index } \\
\hline & \multicolumn{2}{|l|}{ Model 1} & \multicolumn{2}{|l|}{ Model 2} & \multicolumn{2}{|l|}{ Model 3} & \multicolumn{2}{|l|}{ Model 4} & \multicolumn{2}{|l|}{ Model 5} \\
\hline & $B, \beta$ & SE & $B, \beta$ & SE & $B, \beta$ & SE & $B, \beta$ & SE & $B, \beta$ & SE \\
\hline Psychological maltreatment (composite) & $-0.011,-0.016$ & 0.020 & $0.033,0.044$ & 0.022 & $0.049^{*}, 0.070$ & 0.020 & $0.014,0.022$ & 0.018 & $0.022,0.044$ & 0.014 \\
\hline Physical maltreatment (composite) & $0.103^{\star}, 0.178$ & 0.017 & $0.074^{\star}, 0.120$ & 0.018 & $0.041^{\star}, 0.071$ & 0.016 & $0.049^{\star}, 0.095$ & 0.015 & $0.066^{\star}, 0.160$ & 0.012 \\
\hline Maternal age & $0.006,0.028$ & 0.005 & $0.002,0.010$ & 0.005 & $0.014^{*}, 0.072$ & 0.005 & $-0.009,-0.047$ & 0.005 & $0.003,0.025$ & 0.003 \\
\hline Maternal race & $0.123^{*}, 0.048$ & 0.062 & $0.095,0.035$ & 0.067 & $0.118,0.046$ & 0.062 & $0.041,0.018$ & 0.057 & $0.096^{\star}, 0.052$ & 0.044 \\
\hline Maternal education & $-0.060^{*},-0.091$ & 0.018 & $-0.047^{\star},-0.067$ & 0.020 & $-0.086^{*},-0.130$ & 0.018 & $-0.014,-0.023$ & 0.017 & $-0.053^{*},-0.114$ & 0.013 \\
\hline Below poverty line & $0.132^{*}, 0.056$ & 0.061 & $0.178^{\star}, 0.072$ & 0.066 & $0.218^{*}, 0.092$ & 0.061 & $-0.145^{\star}, 0.070$ & 0.056 & $0.088^{*}, 0.053$ & 0.043 \\
\hline Maternal smoking & $0.186^{\star}, 0.074$ & 0.061 & $0.047,0.018$ & 0.065 & $0.090,0.036$ & 0.061 & $-0.064,-0.029$ & 0.056 & $0.073,0.041$ & 0.043 \\
\hline Maternal drinking & $-0.025,-0.011$ & 0.056 & $0.077,0.031$ & 0.060 & $-0.075,-0.032$ & 0.056 & $0.011,0.005$ & 0.051 & $-0.006,-0.003$ & 0.039 \\
\hline Maternal BMI & $-0.004,-0.023$ & 0.004 & $-0.004,-0.028$ & 0.004 & $0.004,0.028$ & 0.004 & $-0.003,-0.022$ & 0.003 & $-0.002,-0.015$ & 0.002 \\
\hline Maternal impulsivity & $0.208^{\star}, 0.108$ & 0.047 & $0.109^{\star}, 0.054$ & 0.050 & $0.161^{\star}, 0.083$ & 0.046 & $0.091^{\star}, 0.053$ & 0.042 & $0.137^{\star}, 0.100$ & 0.032 \\
\hline Maternal depression & $-0.055,-0.018$ & 0.073 & $-0.096,-0.029$ & 0.078 & $0.033,0.011$ & 0.072 & $-0.037,-0.014$ & 0.066 & $-0.042,-0.019$ & 0.051 \\
\hline Parenting stress & $-0.035,-0.023$ & 0.037 & $0.024,0.015$ & 0.040 & $0.020,0.013$ & 0.037 & $0.047,0.035$ & 0.034 & $0.016,0.015$ & 0.026 \\
\hline Parental incarceration & $0.092,0.047$ & 0.049 & $0.109^{\star}, 0.053$ & 0.052 & $0.142^{\star}, 0.072$ & 0.049 & $0.073^{\star}, 0.042$ & 0.045 & $0.102^{\star}, 0.073$ & 0.034 \\
\hline$n$ & 1774 & & 1771 & & 1777 & & 1785 & & 1786 & \\
\hline
\end{tabular}

W4, wave 4; $B$, unstandardized coefficient; $\beta$, standardized coefficient.

Child participants were born between 1998 and 2000; dietary measures were collected between 2003 and 2006, when children were approximately 5 years old; child maltreatment measures were collected at the 3 -year follow-up (W3, 2001-2003, when children were approximately 3 years old) and the 5-year follow-up (W4, 2003-2006, when children were approximately 5 years old). Data were analysed for the current project in the summer and autumn of 2017

$P<0.05$ 
can be explained by the co-occurrence of physical and psychological maltreatment of children by parents.

\section{Discussion}

While a number of factors have been identified as influential in childhood obesogenic food consumption $^{(37,38,46,47)}$, one potential modifiable risk factor that is typically overlooked is maltreatment - both psychological and physical. Our findings revealed that child maltreatment is significantly predictive of obesogenic food consumption and that these findings are largely driven by acts of physical maltreatment. Substantively speaking, child maltreatment also consistently emerged as one of the strongest predictors of obesogenic food consumption in these models. Ultimately, the results suggest that efforts to alleviate children's exposure to acts of parent-child aggression, particularly in the form of physical maltreatment, might also have the added benefit of improving children's dietary behaviours. Although the present study does not explicitly link this process to adult health and health behaviours, it points to a possible pathway explaining a number of prior studies linking child maltreatment to adolescent and adult health ${ }^{(29,30)}$, including adult dietary behaviours ${ }^{(31)}$.

Despite the robust associations between maltreatment of children and their dietary behaviours, our study is not without its limitations. First, although the study employs longitudinal data, the associational nature of our study precludes us from definitively determining the mechanisms that might inform the link between maltreatment and obesogenic dietary practices of children. Still, a number of scholars have highlighted the plausibility of problematic eating and food-related behaviours as a key explanation of the link between adverse childhood experiences (e.g. maltreatment) and obesity, and the need for more research testing this possibility ${ }^{(48,49)}$. We echo these sentiments and advocate for a more robust body of work on these topics moving forward. Second, it would have been preferable to have additional details in our food dimensions beyond salty snacks, sweets, soda and fast food (e.g. a more comprehensive battery of food items, micronutrients). Still, other studies exploring child diet have employed a similar set of items to tap obesogenic consumption patterns in children ${ }^{(46,50)}$. Relatedly, details concerning parental dietary behaviours would have also been preferred, although we were able to control for a number of maternal factors that correlate with dietary behaviours, such as impulse control $^{(51)}$, depression ${ }^{(52)}$ and other health lifestyle behaviours that cluster with dietary intake (e.g. alcohol intake, smoking) ${ }^{(53)}$. Third, the CTS-PC measure of maltreatment in the FFCWS only covers maltreatment items that are considered relatively minor and not severe violence against children (e.g. choking, burning and/or threatening with weapon). Even so, the current items are age appropriate (i.e. children were 3 and 5 years old at the waves examined) and have been used in prior research on maltreatment employing FFCWS ${ }^{(43,45)}$. Fourth, while maternal self-control was accounted for in the analysis, future research should explore the role of self-control in connecting adversities to eating behaviours during childhood, particularly in light of the literature linking nutrition and adverse childhood experiences to impulse control deficits and associated problem behaviours ${ }^{(17,54,55)}$. Finally, future longitudinal analyses examining the influence of early maltreatment on food purchasing behaviour during later life stages (e.g. adolescence and/or early adulthood) would be worthwhile.

Paediatricians and other medical and health professionals regularly encounter obese children in their practice. As such, they are well positioned to consider the role of parent-to-child aggression in the early formation of high-risk health behaviours that, if continued, can jeopardize health at later life stages. A major implication of the present study is that one early pathway to diminishing unhealthy eating practices of children may involve reducing maltreatment, although additional research is needed to move beyond the associational nature of the current study. Still, knowledge concerning the clustering of maltreatment and obesogenic food consumption among children that emerged herein can prove useful in the effort to implement innovative public health programmatic strategies that are multisector and involve a variety of service providers. In short, multi-professional teams of paediatricians, nurses, educators, dietitians/nutritionists and social workers can work together on obesity prevention not only via education, but potentially by decreasing the incidence of maltreatment and its manifold deleterious consequences as well ${ }^{(39)}$. At the macro policy level, extant school nutrition programmes are effective at alleviating food insufficiency ${ }^{(56)}$, although they continually need to enhance the quality of food that is offered. Although findings from the present study are among the first to reveal a link between forms of child abuse and obesogenic eating behaviours, further study into the specific mechanisms that drive the associations identified is warranted.

\section{Acknowledgements}

Financial support: This research received no specific grant from any funding agency in the public, commercial or notfor-profit sectors. Conflict of interest: The authors report no conflict of interest. Authorship: D.B.J. developed the hypothesis, managed the data, performed the analysis, created tables/figures and wrote the first draft of the manuscript. M.G.V. consulted on the methodology, edited tables/figures, made edits to the initial draft of the manuscript, and wrote portions of the introduction and discussion of the manuscript. Ethics of human subject participation: This study was conducted according to the guidelines laid down in the Declaration of Helsinki and all procedures 
involving human subjects were approved by The University of Texas at San Antonio Institutional Review Board. Written/ verbal informed consent was obtained from all subjects.

\section{References}

1. Swinburn BA, Sacks G, Hall KD et al. (2011) The global obesity pandemic: shaped by global drivers and local environments. Lancet 378, 804-814.

2. Ebbeling CB, Pawlak DB \& Ludwig DS (2002) Childhood obesity: public-health crisis, common sense cure. Lancet 360, 473-482.

3. Han JC, Lawlor DA \& Kimm SY (2010) Childhood obesity. Lancet 375, 1737-1748.

4. Popkin BM, Adair LS \& Ng SW (2012) Global nutrition transition and the pandemic of obesity in developing countries. Nutr Rev 70, 3-21.

5. Anderson PM \& Butcher KF (2006) Childhood obesity: trends and potential causes. Future Child 16, 19-45.

6. Cizza G \& Rother KI (2012) Beyond fast food and slow motion: weighty contributors to the obesity epidemic. J Endrocrinol Invest 35, 236-242.

7. Fraser LK \& Edwards KL (2010) The association between the geography of fast food outlets and childhood obesity rates in Leeds, UK. Health Place 16, 1124-1128.

8. Kraak VI, Kumanyika SK \& Story M (2009) The commercial marketing of healthy lifestyles to address the global child and adolescent obesity pandemic: prospects, pitfalls and priorities. Public Health Nutr 12, 2027-2036.

9. St-Onge MP, Keller KL \& Heymsfield SB (2003) Changes in childhood food consumption patterns: a cause for concern in light of increasing body weights. Am J Clin Nutr 78, 1068-1073.

10. Millar L, Rowland B, Nichols M et al. (2014) Relationship between raised BMI and sugar sweetened beverage and high fat food consumption among children. Obesity (Silver Spring) 22, E96-E103.

11. Collison KS, Zaidi MZ, Subhani SN et al. (2010) Sugarsweetened carbonated beverage consumption correlates with BMI, waist circumference, and poor dietary choices in school children. BMC Public Health 10, 234.

12. He FJ \& MacGregor GA (2006) Importance of salt in determining blood pressure in children. Hypertension $\mathbf{4 8}$, 861-869.

13. Tandon PS, Tovar A, Jayasuriya AT et al. (2016) The relationship between physical activity and diet and young children's cognitive development: a systematic review. Prev Med Rep 3, 379-390.

14. Feinstein L, Sabates R, Sorhaindo A et al. (2008) Dietary patterns related to attainment in school: the importance of early eating patterns. J Epidemiol Community Health 62, 734-739.

15. O'Neil A, Quirk SE, Housden S et al. (2014) Relationship between diet and mental health in children and adolescents: a systematic review. Am J Public Health 104, e31-e42.

16. Zahedi H, Kelishadi R, Heshmat R et al. (2014) Association between junk food consumption and mental health in a national sample of Iranian children and adolescents: the CASPIAN-IV study. Nutrition 30, 1391-1397.

17. Jackson D (2016) The link between poor quality nutrition and childhood antisocial behavior: a genetically informative analysis. J Crim Justice 44, 13-20.

18. Ludwig DS \& Nestle M (2008) Can the food industry play a constructive role in the obesity epidemic? JAMA $\mathbf{3 0 0}$, 1808-1811.

19. Kalmakis KA \& Chandler GE (2015) Health consequences of adverse childhood experiences: a systematic review. J Am Assoc Nurse Pract 27, 457-465.
20. Fuemmeler BF, Dedert E, McClernon FJ et al. (2009) Adverse childhood events are associated with obesity and disordered eating: results from a US population-based survey of young adults. J Trauma Stress 22, 329-333.

21. Michopoulos V, Powers A, Moore C et al. (2015) The mediating role of emotion dysregulation and depression on the relationship between childhood trauma exposure and emotional eating. Appetite 91, 129-136.

22. Davis L, Barnes AJ, Gross AC et al. (2019) Adverse childhood experiences and weight status among adolescents. J Pediatr 204, 71.e1-76.e1.

23. Rehkopf DH, Headen I, Hubbard A et al. (2016) Adverse childhood experiences and later life adult obesity and smoking in the United States. Ann Epidemiol 26, 488-492.

24. Mason SM, Austin SB, Bakalar JL et al. (2016) Child maltreatment's heavy toll: the need for trauma-informed obesity prevention. Am J Prev Med 50, 646-649.

25. Hemmingsson E, Johansson K \& Reynisdottir S (2014) Effects of childhood abuse on adult obesity: a systematic review and meta-analysis. Obes Rev 15, 882-893.

26. Blissett J, Haycraft E \& Farrow C (2010) Inducing preschool children's emotional eating: relations with parental feeding practices. Am J Clin Nutr 92, 359-365.

27. Pieper JR \& Laugero KD (2013) Preschool children with lower executive function may be more vulnerable to emotional-based eating in the absence of hunger. Appetite 62, 103-109.

28. Jaffee SR, McFarquhar T, Stevens S et al. (2015) Interactive effects of early and recent exposure to stressful contexts on cortisol reactivity in middle childhood. J Child Psychol Psychiatry 56, 138-146.

29. Bensley L, Van Eenwyk J \& Simmons KW (2003) Childhood family violence history and women's risk for intimate partner violence and poor health. Am J Prev Med 25, 38-44.

30. Crouch E, Strompolis M, Bennett KJ et al. (2017) Assessing the interrelatedness of multiple types of adverse childhood experiences and odds for poor health in South Carolina adults. Child Abuse Neglect 65, 204-211.

31. Abajobir AA, Kisely S, Williams G et al. (2017) Childhood maltreatment and high dietary fat intake behaviors in adulthood: a birth cohort study. Child Abuse Neglect 72, 147-153.

32. Michels N, Sioen I, Braet C et al. (2012) Stress, emotional eating behaviour and dietary patterns in children. Appetite 59, 762-769.

33. Duffy KA, McLaughlin KA \& Green PA (2018) Early life adversity and health-risk behaviors: proposed psychological and neural mechanisms. Ann NY Acad Sci 1428, 151-169.

34. McLaughlin KA, Peverill M, Gold AL et al. (2015) Child maltreatment and neural systems underlying emotion regulation. J Am Acad Child Adolesc Psychiatry 54, $753-762$.

35. Van der Kolk BA, Roth S, Pelcovitz D et al. (2005) Disorders of extreme stress: the empirical foundation of a complex adaptation to trauma. J Trauma Stress 18, 389-399.

36. Hughes SO, Power TG, O'Connor TM et al. (2015) Executive functioning, emotion regulation, eating self-regulation, and weight status in low-income preschool children: how do they relate? Appetite 89, 1-9.

37. Braden A, Rhee K, Peterson CB et al. (2014) Associations between child emotional eating and general parenting style, feeding practices, and parent psychopathology. Appetite $\mathbf{8 0}$, 35-40.

38. Patrick H, Nicklas TA, Hughes SO et al. (2005) The benefits of authoritative feeding style: caregiver feeding styles and children's food consumption patterns. Appetite 44, 243-249.

39. Harper E, Ekvall S, Ekvall V et al. (2014) The nutritional status of children with suspected abuse. In Pharmacology and Nutritional Intervention in the Treatment of Disease, pp. 327-336 [F Atroshi, editor]. London: InTech. 
40. Cui N, Ji X \& Liu J (2018) Child physical abuse, non-anemic iron deficiency and behavior problems. J Pediatr Nurs 39, 74-79.

41. Baker RD \& Greer FR (2010) Diagnosis and prevention of iron deficiency and iron-deficiency anemia in infants and young children ( $0-3$ years of age). Pediatrics 126, 1040-1050.

42. Lonnerdal B (2000) Dietary factors influencing zinc absorption. J Nutr 130, 5S Suppl., 1378S-1383S.

43. Taylor CA, Guterman NB, Lee SJ et al. (2009) Intimate partner violence, maternal stress, nativity, and risk for maternal maltreatment of young children. Am J Public Health 99, 175-183.

44. Straus MA, Hamby SL, Finkelhor D et al. (1998) Identification of child maltreatment with the Parent-Child Conflict Tactics Scales: development and psychometric data for a national sample of American parents. Child Abuse Neglect 22, 249-270.

45. Guterman NB, Lee SJ, Taylor CA et al. (2009) Parental perceptions of neighborhood processes, stress, personal control, and risk for physical child abuse and neglect. Child Abuse Neglect 33, 897-906.

46. Jackson DB \& Johnson KR (2017) Does breast-feeding reduce offspring junk food consumption during childhood? Examinations by socio-economic status and race/ethnicity. Public Health Nutr 20, 1441-1451.

47. Lundahl A \& Nelson TD (2015) Sleep and food intake: a multisystem review of mechanisms in children and adults. $J$ Health Psychol 20, 794-805.

48. Cox R, Skouteris H, Hemmingsson E et al. (2016) Problematic eating and food-related behaviours and excessive weight gain: why children in out-of-home care are at risk. Aust Soc Work 69, 338-347.

49. Hemmingsson E (2018) Early childhood obesity risk factors: socioeconomic adversity, family dysfunction, offspring distress, and junk food self-medication. Curr Obes Rep 7, 204-209.

50. Jackson DB \& Vaughn MG (2017) Parental incarceration and child sleep and eating behaviors. J Pediatr 185, 211-217.

51. Ames SL, Kisbu-Sakarya Y, Reynolds KD et al. (2014) Inhibitory control effects in adolescent binge eating and consumption of sugar-sweetened beverages and snacks. Appetite 81, 180-192.

52. Rahman A, Patel V, Maselko J et al. (2008) The neglected ' $m$ ' in $\mathrm{MCH}$ programmes - why mental health of mothers is important for child nutrition. Trop Med Int Health 13, 579-583.

53. Ma J, Betts NM \& Hampl JS (2000) Clustering of lifestyle behaviors: the relationship between cigarette smoking, alcohol consumption, and dietary intake. Am J Health Promot 15, 107-117.

54. DeLisi M (2017) Consumptive behavior, eating behavior, and antisocial behavior: the ubiquitous roles of self-control. Prev Med 105, 366-367.

55. Craig JM, Piquero AR, Farrington DP et al. (2017) A little early risk goes a long bad way: adverse childhood experiences and life-course offending in the Cambridge study. $J$ Crim Justice 53, 34-45.

56. Ratcliffe C, McKernan SM \& Zhang S (2011) How much does the Supplemental Nutrition Assistance Program reduce food insecurity? Am J Agric Econ 93, 1082-1098. 